\title{
The Journal of Nanoparticle Research victim of an organized rogue editor network!
}

\author{
Nicola Pinna • Guylhaine Clavel • Mihail C. Roco
}

Received: 10 November 2020 / Accepted: 17 November 2020 / Published online: 16 December 2020

(C) The Author(s) 2020

Following attacks on large companies, government bodies, and political parties, will scientific journals be the next victims of large-scale and complex hacks? As far as we know, this has never happened, and we do not see any reason why it should happen in the future. Nonetheless, the publishing race has become increasingly complex and competitive for many years, with individual cases of misconduct all over the world. And while journals equip themselves to prevent the publication of questionable or unreliable scientific research, some organized networks are one step ahead.

Indeed, we editors are sadly accustomed to dealing with plagiarism, manipulated data, fake

\footnotetext{
N. Pinna $(\bowtie)$

Institut für Chemie and IRIS Adlershof, Humboldt-Universität zu Berlin, Brook-Taylor-Str. 2, 12489 Berlin, Germany

e-mail: nicola.pinna@hu-berlin.de

G. Clavel, Assistant Editor

Journal of Nanoparticle Research,

34000, Montpellier, France

e-mail: guylhaine@ nanoparticle.org

M. C. Roco

National Science Foundation, 2415 Eisenhower Avenue,

Alexandria, VA 22314, USA

e-mail: jnr.mroco@gmail.com
}

reviewers, and duplicate publications [1-5]. However, very recently, our journal has been attacked in a new way by a sophisticated and organized network.

In the hope that other editors can avoid similar hacks in the future, we will explain and give you a transparent description of what happened, but before that, we would like to shortly describe how we work and what we are looking for at the Journal of Nanoparticle Research. Our journal was one of the first journals dedicated to nanoscience and nanotechnology, founded in 1999 by our editor-in-chief Mihail (Mike) Roco. Since the beginning, it has always been a journal open to contributions and new initiatives and ideas from everybody working in the extremely multidisciplinary field of nanoscience and nanotechnology, with wide international outreach. For this reason, we receive and accept contributions for several disciplines ranging from chemistry, physics, materials science, and engineering to biology, medicine, computer science, and societal impact. For that matter, we have always been looking for new ideas for focused special issues on "transversal" fields; this is a denominator of nanoscience and nanotechnology.

In September 2019, we received a proposal for a special issue on the "Role of Nanotechnology and Internet of Things in Healthcare." We found the proposal very timely and exactly what we were looking for. The proposal was very well written and accompanied by a 
long list of possible contributors with affiliations and email addresses. The special issue was apparently proposed by eminent scientists in the field of computer science and engineering from well-established institutions in Germany and the UK. So far so good. Pinna still remembers that as an email expert, he even checked the headers of the emails we received, which were apparently generated from the university accounts, and also noted that one more university had moved its email services from home hosted to Gmail (N.B. in the past few years almost all the universities in Anglo-Saxon countries have moved to Google or outlook.com mail services). We therefore accepted the proposal, created a special issue entry in our Editorial Manager system, and gave access to it to the three eminent academics to handle manuscripts.

Some months later, we started to see a large amount of manuscripts that were submitted and a part of them accepted in this special issue. At first, we were quite happy that the special issue had attracted many submissions and interest from the community. However, when we started to look at the submissions, we rapidly noted that most of the manuscripts were of a low quality and/ or did not fit with the topic of the special issue. Of course, we acted immediately, but it was already too late because 19 manuscripts among the 80 submissions had been already accepted and/or published.

We immediately started an internal investigation on all the submissions and directly found out that the supposed eminent academics who proposed the special issue had nothing to do with it. The organized group used these individuals' names and their email addresses to hack and manipulate the peer review process. To be more precise, in August 2019, they bought some very similar domain names (presently expired) to the ones of the supposed university addresses. The only differences were "univ" instead of "uni" in one e-mail suffix and "ac.uk" instead of ".ac.uk" in another. Of course, this is a trivial trick, and if we had checked deeply, we would have noticed that the domains were faked and that the emails should have had been generated from outlook.com (and not Gmail) in one case and directly from servers of the university network in the other.

Have we been careless? Probably, but who would have thought scientists would go to that extent, i.e., to organize a whole rogue network and propose a sound and interesting special issue in a scientific journal, just to get few articles published?
In addition to the problems with the guest editor identities, we and the Springer Nature Research Integrity Group (RIG) also uncovered abnormalities with regard to the peer review reports and peer reviewer identities. All of the evidence points to an organized network that tries - in this case successfully - to infiltrate scientific journals with the objective of easily publishing manuscripts from pseudo-scientists or less productive researchers who want to appear in respectable journals.

In the past weeks, we have been carefully checking all the submissions which were not yet accepted, and we have rejected those that clearly could be attributed to the rogue network. Those that seem genuine have been assigned to our associate editors and handled as regular submissions. For the accepted publications not yet in press, their publication has been stopped, and the authors have been contacted. The published articles which fit the scope of the journal are presently undergoing post-publication peer review, and the proper action will be transparently undertaken to preserve the integrity of the scientific record.

When Mike Roco founded the journal, his aim was to promote and disseminate novel results in the field of nanoscience and nanotechnology. Nicola Pinna joined to support him as executive editor in 2012, soon followed by an assistant editor, Guylhaine Clavel, with the motivation to assist authors to improve their submissions and to help enhance the profile and the visibility of the journal. It turned out that in recent years, besides reviewing the good-quality papers, we spend most of our time in prescreening relatively low-quality manuscripts and, as in this extreme case, coping with scientific misconduct under all its facets. We fear that the present case may be only the tip of the iceberg. In the face of the growing scale of misconduct in science publication, we are grateful that Springer Nature supplies their journals with a specialized team (the Research Integrity Group) dedicated to investigating all kinds of misconduct, lifting the weight of these investigations off the scientist editors, but also providing new tools to prevent, detect, prove, and stop such wrongdoing [6].

At the Journal of Nanoparticle Research, we have now implemented more strict processes for avoiding this happening again, but this is definitely not enough to cope with the main problem from which the scientific literature has been suffering in the last few decades, that is, the exponential growth of scientific publications driven by the obligation for scientists in many countries 
to publish more and more, which leads to the publication of a huge background noise of useless and low-level articles. It is indeed a tedious work to extract from the mass of submissions the scientific research that does merit the dissemination of its results. States, funding agencies, and universities should push for high quality science and should avoid to promote and even discourage the exponential increase of the number of publications. As editors, we are committed since many years to our journal and will continue to invest much of our time to work with authors to promote nanoscience and nanotechnology in our journal by applying the highest standards thanks to the dedicated work of our associate editors and reviewers, but it is also clear that under the present circumstances, it is rarely rewarding and fun.

Funding Open Access funding enabled and organized by Projekt DEAL.

Open Access This article is licensed under a Creative Commons Attribution 4.0 International License, which permits use, sharing, adaptation, distribution and reproduction in any medium or format, as long as you give appropriate credit to the original author(s) and the source, provide a link to the Creative Commons licence, and indicate if changes were made. The images or other third party material in this article are included in the article's Creative
Commons licence, unless indicated otherwise in a credit line to the material. If material is not included in the article's Creative Commons licence and your intended use is not permitted by statutory regulation or exceeds the permitted use, you will need to obtain permission directly from the copyright holder. To view a copy of this licence, visit http://creativecommons. org/licenses/by/4.0/.

\section{References}

1. Promoting integrity in scholarly research and its publication. https://publicationethics.org/

2. Rougier NP, Timmer J (2018) Ten Simple Rules for Scientific Fraud \& Misconduct. PeerJ Prepr 6:e27395v1. https://doi. org/10.7287/peerj.preprints.27395v1

3. Byrne J (2019) We need to talk about systematic fraud, Nature $566: 9$

4. Brainard J, You J (2018) What a massive database of retracted papers reveals about science publishing's 'death penalty'. Science. https://doi.org/10.1126/science.aav8384

5. Coudert F-X (2019) Correcting the Scientific Record: Retraction Practices in Chemistry and Materials Science. Chem Mater 31(10):3593

6. https://www.springernature.com/fr/editors/research-integrity

Publisher's note Springer Nature remains neutral with regard to jurisdictional claims in published maps and institutional affiliations. 